This is an electronic reprint of the original article. This reprint may differ from the original in pagination and typographic detail.

Author(s): Karjaluoto, Heikki; Huhtamäki, Maija

Title: The role of electronic channels in micro-sized brick-and-mortar firms

Year: $\quad 2010$

Version:

Please cite the original version:

Karjaluoto, H., \& Huhtamäki, M. (2010). The role of electronic channels in micro-sized brick-and-mortar firms. Journal of Small Business and Entrepreneurship, 23(1), 17-38. https://doi.org/10.1080/08276331.2010.10593471

All material supplied via JYX is protected by copyright and other intellectual property rights, and duplication or sale of all or part of any of the repository collections is not permitted, except that material may be duplicated by you for your research use or educational purposes in electronic or print form. You must obtain permission for any other use. Electronic or print copies may not be offered, whether for sale or otherwise to anyone who is not an authorised user. 


\section{THE ROLE OF ELECTRONIC CHANNELS IN MICRO-SIZED BRICK-AND-MORTAR FIRMS}

Heikki Karjaluoto, Professor in Marketing at the University of Jyvaskyla* Maija Huhtamäki, Research Assistant in Marketing at the University of Oulu

\begin{tabular}{|l|l|}
\hline *Corresponding author & \\
$\begin{array}{l}\text { Dr Heikki Karjaluoto } \\
\text { School of Business and Economics }\end{array}$ & M.Sc. Maija Huhtamäki \\
PO Box 35 (Building MaE) & Faculty of Economics and Business \\
FIN-40014 University of Jyvaskyla & Administration \\
Finland & PO Box 4600 \\
e-mail: heikki.karjaluoto@econ.jyu.fi & Finland \\
Tel: +358445361637 & e-mail: $\underline{\text { maijahuh@ mail.student.oulu.fi }}$ \\
Fax: +35885532906 & Fax: +35885532906 \\
& \\
\hline
\end{tabular}

Heikki Karjaluoto is a Professor in marketing at the University of Jyvaskyla, Finland. His research interests include electronic business in general and mobile business and commerce in particular. Previous publications have appeared in the International Journal of Bank Marketing, Internet Research, International Journal of Retail \& Distribution Management, International Journal of Mobile Marketing, Journal of Services Marketing, among others.

Maija Huhtamäki works as a Research Assistant in marketing at the University of Oulu, Finland. Her research interests are in small business and entrepreneurship and electronic business. 


\title{
THE ROLE OF ELECTRONIC CHANNELS IN MICRO-SIZED \\ BRICK-AND-MORTAR FIRMS
}

\begin{abstract}
The purpose of this study is to increase understanding of the role of electronic channels in micro-sized brick-and-mortar firms, which are just starting to utilize new channels in the promotion of their goods and services. With the use of a multiple case study method containing ten cases, the study first identifies external and internal factors affecting the adoption and use of e-channels in micro-sized firms. Secondly, the results propose, in line with previous literature, that different e-channel utilization levels can be identified. The paper provides both theoretical and managerial implications.
\end{abstract}

Keywords: electronic channels, facilitator, inhibitor, level of e-channel utilization

\section{Introduction}

Information technology has changed the ways of doing business and, accordingly, has had an effect on marketing as well. The digital environment enhances processes and activities across the entire organisation (Strauss, El-Ansary and Frost 2006, 6). Electronic channels provide companies with many possibilities to manage their activities in novel ways. Ecommerce and the Internet have many potential advantages with regard to both reaching out to new customers and ameliorating existing customer relationships (Fillis, Johansson and Wagner 2003). In the long run the adoption of electronic channels can reduce both human and financial resource needs (Pires and Aisbett 2003). This is a key issue, since small firms usually have very limited resources, not only financially but with regard to human resources as well. Issues like two-way communication, differentiation of customer strategies and 
customization, which are all essential elements of relationship marketing, can be facilitated by using digital channels as a way to communicate with the customers. Electronic channels enable increased self-service, which makes it possible for customers to seek information and order products or services at the time and place best suited for their needs (Payne and Frow 2004). Despite the opportunities of electronic channels, some small firms may perceive the use of electronic channels only as a reactive response to the actions of competitors, rather than a proactive development of value-adding services, which it could be (Daniel and Wilson 2002).

As information technology continues to pervade every sector of business, the use of electronic channels, like the use of e-mail and web pages, has to some extent become almost an imperative for companies. The objective of the study is to determine the various factors that influence the adoption and utilization of electronic channels in micro-sized firms. In addition to this, the study aspires to increase understanding of how micro companies utilize electronic channels and information networks in marketing. The study proposes a conceptual model with empirical assessment depicting the role of electronic channels in micro-sized firms, portraying both the contextual factors influencing the adoption of e-channels and the different levels that can be identified with respect to e-channel utilization.

There has been plenty of previous research on e-commerce in general. However, studies that focus on the adoption and use of e-business strategies in micro firms are relatively scarce (Levenburg, Dandridge and Hong 2001; Daniel and Wilson 2002). It should be noted that small businesses are not necessarily simpler versions of large companies or even similar (Matlay 2000). Schaper, Campo and Imukuka (2005) remark that the SME (small and medium enterprises) sector is not a homogenous group of firms, but is made up of micro-, small- and medium-size companies, which can in fact have quite contrasting characteristics. In this study the phenomenon is examined in the context of micro-sized firms. 
Here, in accordance with the definition of the European Commission (2006), the term micro firm refers to a firm with less than 10 employees. These very small companies of a traditional nature (or even entrepreneurs) are not necessarily used to utilizing the potential of information technology but could potentially benefit from it.

The focus of this research is not to study e-commerce in the traditional, narrow sense as buying and selling of goods or services on the Internet, but to examine the adoption of electronic channels and the ways in which a micro-sized firm can utilize them when interacting with customers. The focus of this study is on the transition of traditional (brickand-mortar) companies into clicks-and-mortar organizations. Clicks-and-mortar organizations are companies that conduct some e-commerce activities but their primary business is done in the physical world (Turban et al. 2002, 6). The utilization of electronic channels is examined from a marketing point of view. The study focuses on the question how electronic channels can enhance the management of customer relationships and, ultimately, the company's performance.

This article is structured as follows. Firstly, the authors discuss some issues concerning the factors that influence electronic channel utilization and different approaches to modeling e-business development in small firms. The conceptual model for the study is presented at the end of the theoretical section, after which the authors describe briefly the research strategy and the cases involved. Finally, the authors present the result of the empirical study and propose their conclusions and the managerial implications resulting from the study.

\section{Factors Influencing the Adoption and Use of Electronic Channels in Micro Firm}

\section{Context}

When examining e-commerce issues, it is necessary to pay attention not only to the technological aspects but to the business aspects as well. According to Ramsey et al. (2003), 
the core of e-commerce is to effectively match the effort to create superior value with the technical capabilities of the new medium. It is frequently stated in the literature concerning ebusiness use in SMEs that there are several barriers which inhibit small firms from using ebusiness and related technologies (Poon and Swatman 1999; Fillis, Johansson and Wagner 2003; Levy, Powell and Worrall 2005; MacGregor and Vrazalic 2006). For example, Levy, Powell and Worrall (2005) summarize several e-business inhibitors, including implementation costs, limited financial resources, and insufficient knowledge or experience. Since utilizing technologies in SMEs is clearly problematic, it is important to examine if the problems occur in micro firms as well, and to show how a micro company could benefit from these technologies in its marketing. Moreover, there is reason to believe that the barriers to ebusiness development in SMEs, such as scarce resources or the lack of skills to use electronic channels, become even more evident in micro firms.

Even though there are factors which potentially inhibit e-business development in small firms, many things contribute to e-business development as well. Small firms are, for instance, usually more flexible and able to implement changes quicker than larger firms due to a lean organizational structure and centralized decision-making. In many countries the number of micro firms is larger than any other firm category (Fillis, Johansson and Wagner 2003; Schaper, Campo and Imukuka 2005), and thus they are a significant part of the economy.

There are many internal and external factors which are considered to be of importance when examining e-business adoption and development in micro-sized firms. The examination of these contextual factors is largely grounded on Fillis and Wagner's (2005) model of small firm e-business development, which they have developed through several studies (Fillis, Johansson and Wagner 2003; 2004). Other studies are used to complement the examination. 
The relevant factors are grouped into three groups: firm-specific and owner-managerial factors, resource-related factors, and environmental factors.

\section{Firm-Specific and Owner-managerial Factors}

Firm-specific and owner-managerial factors are one of the most notable characteristics of micro firms (Fillis, Johansson and Wagner 2003; Ramsey et al. 2003; Schaper, Campo and Imukuka 2005). Firm-specific factors and managerial factors often merge because the owner-manager has such a strong influence over the whole firm (Fillis, Johansson and Wagner 2003). Literature states that the most important factors of firmspecific and owner-managerial relating to e-business development are managerial factors such as motivation, know-how and skills (Matlay 2000; Martin and Matlay 2001; Fillis, Johansson and Wagner 2004; Schaper, Campo and Imukuka 2005) and firm orientation (market orientation and/or entrepreneurial vs. conservative approach) (Fillis, Wagner and Johansson 2003; 2004; Ramsey et al. 2003; Fillis and Wagner 2005; McCole and Ramsey 2005).

\section{Resource-related Factors}

The resources (human, financial and technical) of micro firms are very limited, and this may inhibit the adoption and use of electronic channels (Ramsey et al. 2003). As small firms often have strict financial constraints (Thong 1999) and e-business typically involves high initial set-up costs (Taylor and Murphy 2004), micro firms have been reluctant to invest in e-business solutions. However, the costs have fallen greatly during the last few years and even quite advanced applications are available to small companies with relatively low costs (Stone 2003).

\section{Environmental Factors}

Fillis, Johansson and Wagner (2003) argue that specific industry and sectorial factors affect the SME in its need for e-business. Since the way of doing business and marketing is 
different in each market (e.g., B2B vs. B2C), the market in question naturally influences the opportunities that electronic channels can provide. The competitive situation in the market can also be seen as an influencing factor. If the competitors have adopted some level of ecommerce, the firm can be compelled to develop its own e-business capabilities in order to stay competitive. Finally, customers as well as the value chain can put pressure on the adoption of e-business (Al-Qirim 2006).

\section{The Adoption and Use of Electronic Channels}

\section{Stage Models of E-business Development}

A variety of stage models for e-business or e-commerce development are presented in academic literature (Table 1).

"Inset Table 1 about here"

Even though different stage models of e-business development are presented here, it is not argued that the adoption of e-commerce or e-business is in reality a straightforward process which proceeds from the less sophisticated stages to the more sophisticated ones. Rather, these are only presented in order to formulate a clearer picture of the possible degrees of electronic channel use that different companies might adopt, as well as their potential benefits.

Martin and Matlay (2001) have reviewed the UK government's Department of Trade and Industry's (DTI) e-business adoption ladder (see also Taylor and Murphy 2004). In the DTI-model the process of adopting electronic channels is divided into five stages. For 
instance, the first stage is the use of e-mail as a medium for efficient internal and external communication. In the fifth phase, "transformed organizations", which is the most sophisticated of them all, there are open information systems for customers, suppliers and other partners and the business is based on interworking between organizations and individuals. As the company proceeds from one stage to another, the business benefits are seen to increase, and the extent of organizational change and sophistication increase as well. Rao, Metts and Mora Monge (2003) depict e-commerce as a four-stage development process, each stage having its own facilitators and inhibitors. Costs, technological demands and complexity are seen to rise in later stages. The first stage ("presence") is where the organization has a static "window on the Web" that provides information and one-way communication. In the second stage ("portals"), two-way communication is introduced. The third stage is entitled "transactions integration". At this stage, financial transactions can be made and internal processes are integrated. The fourth stage ("enterprises integration") is characterized by integration of online and offline channels. Here, it means using e-commerce for customer relationship management (CRM) and supply chain management (SCM).

Even though the authors present a stage model, they, too, acknowledge that a company does not necessarily begin at the first stage and progress through all the later stages. Moreover, they include in their model various facilitators and barriers which influence the firm at each stage. However, their model focuses only on the website, not for example on the use of e-mail and the Internet for marketing communication. Especially the fourth stage is too technologically complex to be applied to the context examined here.

Establishing a website is usually one of the first operations a company does when it starts to develop its e-commerce activities. Foley and Ram (2002) see that information and communication technology (ICT) can be introduced into the firm's different functions at different times. They argue that the Internet can be used for three increasingly sophisticated 
activities: one, for publishing and publicizing information on the web site; two, for interacting with customers and suppliers through communication systems and; three, for transforming the way business activities are carried out. However, the model by Foley and Ram is not applicable in this study as such, for the reason that micro-sized firms are so small that the activities of the firm are not separate.

Chau (2003) presents a four-phase model of SME e-commerce utilization and business transformation. Chau distinguishes between experimental and strategic use of ecommerce. In experimental use, e-commerce is considered a supporting tool, and when ecommerce is used strategically, it is seen to leverage new business opportunities and benefits. Experimental use was found to be more common in SMEs. The first two phases are seen as experimental use and the third and fourth phase as strategic. SMEs in phase one spend minimal resources on e-commerce, and it is used primarily for a static presence on the Internet. Firms belonging to the second group (phase two) use more resources for enhancing ways of communication or for providing alternative trading systems. In the third phase ecommerce is integrated into existing business processes, whereas firms in phase four are fully dependent on the use of e-commerce, since e-commerce forms a major part of their business proposition. The level of business transformation is seen to increase in accordance with the strategic motivation to use e-commerce. The benefits associated with e-commerce are seen to increase from phase to phase as well.

\section{Alternative Perspectives}

It is evident that stage models as such have many limitations. In reality it is difficult to distinguish distinct phases of e-business development, especially in small firms where ebusiness activities can develop in a non-linear, discontinuous fashion (Ramsey et al. 2003). 
The most "sophisticated" phase of development is not necessarily the desired state. The stage of ideal e-business development depends on the numerous factors presented earlier. The development should always reflect and be appropriate to the needs and goals of the organization (Stone 2003; Fry et al. 2004). In many companies that offer certain services the whole process cannot be replaced electronically, like for example at a hairdresser's, where the service is produced in interaction with the customer. However, some processes can be carried out via electronic channels. The service provider could for example build an electronic booking system.

The DTI adoption ladder has received a lot of criticism. According to Martin and Matlay (2001), it ignores the small firms' inhibitors and motivators that affect the development of their e-channel utilization, and they suggest that adopting e-business is beneficial to all small firms and that the goal is the same for every firm. Taylor and Murphy (2004), too, see the DTI adoption ladder as deterministic and, according to them, it implies that all SMEs have similar needs and opportunities to follow a certain path in developing their e-business techniques, and if this path is not followed, it is seen as a failure. Fillis, Johansson and Wagner (2003) call stage models "formalised, prescriptive frameworks". They emphasize the fact that there are several tangible and intangible factors that influence the process of e-business development. Bahn and Fischer (2003) present a classification of five approaches to balancing the strategy and operations with electronic commerce in brick-andmortar companies (see table 2).

"Take in Table 2 about here"

The first approach, "front lobby", can hardly even be considered a strategic approach, since there the firms that have taken this approach often have not made any articulated plan 
for e-commerce. The approach resembles many small firms' initial efforts of using electronic channels, but for some firms this is the desired state of e-commerce. The importance of ecommerce operations increases from the first approach to the fifth. The fifth approach, "direct integration", represents the strongest integration of e-commerce and brick-and-mortar operations. Here, a sense of multi-channel brand is created. The fifth approach, which is closest to an actual strategy for e-commerce, was found to be the most rarely used rarely.

\section{Conceptual Model}

Based on the theoretical discussion, a model depicting the role of e-channels in micro firms is formulated. In this conceptual model, the influencing factors of the micro firm context are combined with the classification of different levels of e-channel utilization (see figure 1).

"Take in Figure 1 about here"

The influencing factors are grouped into three categories. Firm-specific and ownermanagerial factors include the orientation of the firm (entrepreneurial vs. conservative and whether the firm is market-oriented), know-how and skills (including technological proficiency), background, perceived benefits (or awareness of benefits), motivation and attitude. Resource-related factors consist of financial, technological and human resources. Finally, environmental factors are industry/sectorial, the type of the product or service and market-related factors (customers and competition). These factors can either facilitate or inhibit a firm's electronic channel adoption and use. The impact of the factors depends on the firm, which is why the factors are not pre-determined as facilitators or inhibitors. The owner- 
manager's know-how of e-business and strong motivation to develop the company's use of echannels, to name a couple of examples, can act as facilitators.

The level of e-channel utilization is seen to depend on the influencing factors. The optimal level of development is different for each firm. The objective is to leverage the benefits of physical presence (brick-and-mortar) and the benefits of online presence (Turban et al. 2002, 103-104). The conceptual model presented distinguishes four levels of e-channel utilization in brick-and-mortar micro firms. It is suggested that, from the outsider's perspective, different levels of e-channel utilization can be identified, whereas from the firm's perspective these levels are not necessarily considered stages of development. Instead, the firm has adopted a certain approach. However, if the factors influencing the firm change, the firm's approach might change as well, and thus the company could move to another level. The firm might, for example, no longer find the role of e-channels only informational, but a possible channel for sales transactions. The firm can have a clear incentive to change, but, equally, the firm can choose to remain at a certain level. Moreover, companies do not necessarily begin from the first level or they can skip some levels (see for example Rao, Metts and Mora Monge 2003).

The first level of the model is entitled informational level. Firms at this level see electronic channels primarily as a medium for searching for and providing information. The second level of e-channel utilization is the communicational level. The role of electronic channels at this level is greater than at the previous level. The website of the company is more advanced, and it can for example enable communication between the firm and the customers with the help of feedback and/or contact forms. There can also be a list of frequently asked questions and a search facility on the site. The use of e-mail to contact customers is more systematic than at the first level. 
The third level is entitled the transactional level. The companies acknowledge the importance of electronic channels as a marketing channel and might for example use them for advertising. Search engine marketing might be employed as well. There are various ways to do search engine marketing and thus increase the website's visibility: These include keyword-related banner advertisements on the search-results page; paid submission and paid inclusion for regular updates (in other words, the website is reviewed within a fixed time frame and shows up on the search-results page); search engine optimization (that is to say, modifying site codes to make the site more relevant and more search engine compatible); and paid placements (the company has paid for the site to appear in the sponsored section of the search-results page) (Ravi 2005). At this level, an elementary e-shop (a facility for ordering products) can exist, but it does not include a possibility to pay online. Since all products or services cannot be distributed via online channels, additional and/or supportive services can still be provided (Bahn and Fischer 2003). The fourth level, entitled "integrated part of business", represents the highest level of e-channel utilization included in this study. At this level the electronic channel is seen both as a marketing channel and a channel for doing business. This level contains for instance web shops with online transaction and payment capabilities. In other words, offline and online channels are integrated. However, the online channel is still considered to be secondary to the offline channel, which is corresponds with Bahn and Fischer's (2003) “parallel lines” approach.

As mentioned earlier, the strategic alignment between traditional business and ebusiness is important in order to derive benefits from e-channel utilization (Bahn and Fischer 2003; Ramsey et al. 2003). As the role of e-channels becomes more significant, the need for strategic alignment and technological sophistication are seen to increase. Adelaar, Bouwman and Steinfield (2004) have found that the higher the level of clicks-and-mortar integration is, the higher are the possibilities for synergies between online and offline channels. They also 
note, however, that higher integration also indicates higher IT investments and intangible organizational costs.

\section{Methodology}

\section{The Case Study Approach}

Case studies can be divided into two categories, namely single- and multiple case study designs (Yin 2003). This study is a multiple-case study, and the cases are different micro-sized firms. Case study is the preferred strategy when the research question is descriptive in nature and when the researcher has little control over the events (Yin 2003, 1). In this study the context of a micro firm is seen to have a considerable influence on the researched phenomenon. Here, a multiple case study is a justified choice because analytical conclusions arising from more than one case have more weight than those derived from only one single case. Moreover, it is likely that the cases differ somewhat from each other and if common conclusions can be made from these different circumstances, the generalizability of the findings increases.

\section{Empirical Data Collection}

The empirical data was gathered from eight micro-sized companies. The primary data collection method was the semi-structured interview, and a total of 15 interviews were conducted. In this study, interviews were used as a method of gathering empirical data because they produce rich, in-depth and multifaceted data. The interviewees were the ownermanagers of the case firms. In addition to the interviews, secondary data sources such as company websites and reports (if available) were used to validate the interview material. The interviews were audio recorded and transcribed for analysis. According to Eisenhardt (1989), 
the first stage in case analysis is within-case analysis, which familiarizes the researcher with each case and helps in the next phase, cross-case comparison. In addition to the within-case analysis, the researchers conducted a cross-case analysis with the help of the case reports of each case firm. One method of analysis in cross-case analysis is categorization, which was used in this study as well. In this study the material was organized into categories or themes according to the theoretical framework. The empirical findings were then analyzed by comparing them to the theoretical framework. Interpreting the results is another phase of qualitative analysis, and this phase is closely connected with the first one.

\section{Case Descriptions}

The companies examined in this study are all micro-sized firms operating in Finland. In general e-business adoption in SMEs and micro-firms has risen steadily in Finland. According to recent statistics (Pk-yritysbarometri, 2007) around 70 percent of all SMEs had a website. A total of 95 percent of SMEs with more than 20 employees had a website whereas 55 percent of micro-firms (five or less employees) had an own website. However, only five percent of SMEs had an online shop and 11 percent provided the possibility to order products or services via an electronic order form.

. The ten case companies are very different in nature. Some of them are one-mancompanies or the owner-managers are sole entrepreneurs. Many of the owner-managers of the firms have extensive experience as entrepreneurs. The case companies and their background information are presented in table 3 .

"Insert Table 3 here" 
All of the case companies are brick-and-mortar firms but they all utilize information technology in one way or another in their business. In total, the use of e-channels was quite limited among the examined firms. Nine out of ten had a website, and on average the websites contained elements like company information, information on the company's products or services and contact information. Initially, none of the firms had websites with a feature that enabled online buying and paying. In some cases the architecture of the site was unclear or the URL was long and difficult to remember.

Generally speaking, electronic channels had initially quite a minor role in the case firms. The Internet was used mainly for general information searching and in day-to-day communication with customers and other partners. In many of the firms marketing was more about maintaining relationships with existing customers and getting new contacts through a personal network. Since the firms are so small, their business is relatively small-scale and their clientele is not very extensive. All the companies were listed in some online directories and could be found via search engines. Marketing of the website through other channels like print advertising was almost nonexistent. None of the firms had utilized search engine marketing, and many owner-managers relied on traditional ways when it came to marketing communication and maintaining customer relationships. For instance, personal selling was seen to be a better way for marketing products and services than e-mail. According to the firms, one of the disadvantages of using e-mail was the ease of ignoring the e-mail message and the vast amount of junk mail. Several interviewees had quite negative attitudes towards e-mail marketing in general. E-channels were seldom the primary channel used in marketing communication and for example the first contact with the customer was often made via some other channel. Nevertheless, electronic channels were considered important. Even if the website was only an electronic brochure, the companies saw that it still had an impact on the company's image. For instance, according to one owner-manager, the poor functionality and 
quality of the website might have a negative influence on the users' impression of the company and its products. Moreover, in some case firms the website was virtually the only means of marketing communication. Even if e-mail was not necessarily seen as an effective way of acquiring new customers or contacting customers for the first time, it was considered a good way of communicating with existing customers. For example, a large part of the communication with existing customers was carried out via e-mail.

\section{Results}

\section{Factors Underlying E-channel Utilization}

\section{Firm-specific and owner-managerial factors}

One of the major barriers to developing e-business activities in both the groups seems to be the lack of knowledge or know-how. Know-how of e-business and marketing in general proved to be significant as well, as know-how related directly to technology. The majority of the firms were not aware of the possibilities of e-business and electronic channels in for example enhancing the efficiency of their operations, which was a major bottleneck for some firms. Many of the owner-managers were also unfamiliar with search engine marketing. One of the downsides of small firms and especially the owner-manager being the sole decisionmaker in the firm is that the decisions can be constricted (Schaper, Campo and Imukuka 2005). This was clearly evident in this study, since in many cases the owner-manager had simply not considered the possibilities that the digital channels could provide. In several cases the firms lacked technological knowledge and skills necessary to for example create web pages. General understanding of e-business varied between the case firms and was not related to the industry. 
The firm's orientation or, in other words, the owner-managers' outlook on doing business became evident in most of the cases. Some firms exhibited more of an entrepreneurial orientation, whereas others seemed to be more conservative. Some ownermanagers seemed to hang on to their beliefs and were somewhat unwilling to accept external ideas or advice. In Articraft's case the company had an entrepreneurial orientation to business, meaning that the owner-managers were innovative, pursued new ways of doing things and were willing to take risks. It can also be said that they were market-oriented, meaning that they aspired to do things differently than their competitors and offer their customers something unique.

"...of course profitability is the key and a prerequisite, it dictates a lot in business, but...we have attempted to look for new ways, at every level, in products and with customers...so that there wouldn't be so much overlapping with other firms. That has been a kind of starting point. Even if copying might be profitable too... we have not wanted to take that road because of our personal views...we're constantly seeking challenges from this [business], too." (Owner-manager, Articraft)

Perhaps a more conservative approach to business could be seen in the case of the interior design firm Holidecor. The owner-manager's lack of self-efficacy seemed to be a major barrier to development, not only when it came to utilizing new technologies but with regard to developing the business in general as well. The owner-manager was somewhat riskaverse, maybe in part because of negative past experiences arising from the fact that the firm had had financial difficulties in the past.

According to the empirical material, age of the firm has an influence on the adoption and use of electronic channels. Many of the case firms had a long history and many of the owner-managers had been working in the field for over a decade. Maybe this is why some of 
them seemed to be very much set in their ways. They had traditional ways of doing business and manifested a certain unwillingness to change and deviate from these familiar processes. In micro firms owner-managers are usually quite alone in the decision-making and this can be a limiting factor in that they do not always see the opportunities to change the way things are done. This is why an owner's long experience can in some cases inhibit the adoption of ebusiness activities. Among the case firms it was easier to make changes if the firm was younger. The motivation of the owner-manager varied greatly with regard to developing ebusiness activities and in some cases also with regard to developing their business in general. Initially, there was a cautious and somewhat skeptical attitude towards e-business among the case firms.

"I don't go around selling myself, I keep a low profile, I don't have a website, I don't have brochures...I don't go to companies to peddle my firm or my services, I don't advertise." (Owner-manager, Ind-Design)

In many of the cases there seemed to be a lack of overall strategic orientation and strategic planning when it came to marketing. This was reflected in the utilization of the potential of electronic channels. In many companies the focus was on the operational, day-today issues of doing business. Many firms had not defined any marketing objectives. In relation to e-channels, sometimes it could be seen that the company had established a website without actually thinking about what its function and objectives were in relation to supporting the firm's business idea.

"...I am kind of already in a stage where I use e-mail, I have a website with a contact form and I do work with the computer all the time and I send files in electronic form and so on...now I should chart the current situation and then think about how the 
process could be done ideally utilizing information technology and then develop towards that ideal...that the use of IT would become an integral part of my business." (Owner-manager, Designor)

\section{Resources}

The lack of resources, both financial and human, was evident in almost all of the cases. Technological resources were not identified as relevant as the other two. In small firms, scarce financial resources are always a barrier to some extent, but in this case limited human resources or, simply put, the lack of time was more of an inhibiting factor than the financial constraints. All of the owner-managers agreed that especially with sole entrepreneurs, the lack of human resources also impedes the general development of business, since the actual productive work takes most of the time, leaving little time for supportive activities like marketing. Some firms were even afraid of engaging in e-business activities because of the limited resources. This is to say that some were concerned that for example establishing a web shop might increase the demand so much that the firm would not be able to respond to it. A somewhat surprising discovery was that when the awareness of e-business was low, the related costs were perceived higher and thus financial resources was seen as an inhibiting factor. As the level of e-channel utilization grows, it does demand more resources to be invested in for example the technological solutions. Technological resources (IT infrastructure, computer sophistication) did not come forth as a major inhibitor, whereas technological know-how and skills seemed to be more significant. In sum, technological or even financial resources did not seem to be amongst the most important factors underlying the decision to engage in e-business activities.

\section{Environmental factors}


In some cases, the business type, or, in other words, the type of product or service, was such that it is not possibly to exploit electronic channels more than to a certain degree. For instance, Entertainer reports that their website only serves the function of a brochure -all their customers come via a travel agent and therefore online presence is not vital for them. Some of the case firms are service providers, and even though theory suggests that intangibility correlates positively with e-commerce, in these firms the service process requires face-to-face contact between the firm and the customer and thus actual online selling of the service is not possible. Nevertheless, in these cases electronic channels were seen to have importance as a supportive channel. For instance, with the industrial design firms, the type of service was identified as a limiting factor, as industrial design services are often long, customized projects, requiring a lot of communication and also face-to-face contact with the customer. In contrast, some of the case firms provided products that could easily be sold via an e-shop, and thus electronic channels could potentially become a sales channel.

In some cases the market-related factors like the competitive situation or the customers seemed to have some influence on the adoption and use of electronic channels in the firm. Ind-Design was the only one of the case firms that did not have a website. It can be said that market factors encourage Ind-Design to utilize e-channels at least by establishing a company website, since the firm itself designs websites for customers and so the fact that the company itself does not have one might seem unprofessional. It is also likely that most of the competitors already have a website.

In almost all of the case firms the need for outside support was evident, even if it was not always articulated. Most firms did, however, acknowledge the importance of getting support from outside the firm. It is possible nowadays to acquire ready-made online shopping solutions from service providers, and thus for example establishing an online shop is made 
relatively easy even for small firms. Personal network or partners outside the company can be of great help as well.

“...when you don't have the know-how yourself, you have to form a network"

(Owner-manager, Finmade)

\section{Identified Levels of E-channel Utilization among Case Firms}

The case firms are evaluated on the basis of the conceptual model in order to illustrate the firms' current state and progress, as well as their anticipated development in the future. The starting point for each case firm was different, even though they all were quite at an early stage in their use of electronic channels. Figure 2 shows the levels of e-channel utilization which were identified in the firms.

"Take in Figure 2 about here"

The firms at the highest level in adoption (Articraft and Frame) use banner advertising and have their own e-shops with online ordering and various payment options. The desired state of e-channel utilization was different for different firms. For some firms the objective was the "integrated part of business" level, but for some, like Ind-Design, the role of electronic channels was seen as more minor in the future as well. In contrast, Finmade, which was at the time of the study at the informational level, aims at being at least on the communicational level. The firm plans to create a development plan concerning the website and customer relationship management and marketing activities in general, planning for example some changes to make their website more "marketing-oriented". Their future plans 
also include sending newsletters to existing customers. In the long run their goal is to target a wider clientele by creating an online shop.

The cases show that there are several factors which influence the initial adoption and the extent of the utilization of e-channels in micro firms, namely firm-specific and ownermanagerial factors, resource-related factors and environmental factors. Literature suggests that these factors influence the utilization either positively (by acting as a facilitator) or negatively (by acting as an inhibitor). The factors marked in bold in Figure 3 signify new factors that emerged from the empirical analysis (namely experience and outside support). Some factors were considered to have a weaker influence than others, and these are marked in grey.

"Take in Figure 3 about here"

Firstly, the internal or firm-specific and owner-managerial factors are focal determinants of e-channel adoption and use. First of all, if the firm or the owner-manager has an entrepreneurial orientation and/or is market-oriented, it somewhat facilitates the utilization and, respectively, if the orientation is more conservative, it can act as inhibitor. Both managerial and technological know-how was found to be important. The lack of know-how and skills hinder the adoption and use, and long experience can also be a hindering factor, since the older the firm is, the harder it can be for it to change ways of action. The perceived benefits or the awareness of the benefits are interrelated with know-how. If the know-how is low, the perceived benefits are usually low, too, and thus they affect the utilization. Human and financial resources are significant when it comes to the utilization of digital channels. Industry or sectorial factors are relevant among the cases investigated in the sense that firms in different businesses have different needs to utilize electronic channels. A new external 
factor was introduced to the model, and this was labeled outside support. Based on the empirical study, this factor proved to be very significant. The availability of outside support is a key factor in the utilization and the lack of outside support can impede the adoption of electronic channels considerably. Outside support is particularly important in micro-firms, since the owner-manager is usually the sole decision-maker, whereas in bigger firms there is more support available within the firm.

Essentially, at the informational level, the role of electronic channels is to provide and facilitate searching for information. At the communicational level the electronic channels are means for two-way communication and interaction between the firm and the customer. At the transactional level the e-channels are seen as a marketing channel. E-channels are possibly also a channel for sales or alternatively a support channel (for example extranet), depending on the type of product or service. "Integrated part of business" refers to the level where echannels are a channel for marketing and doing business and where offline and online channels form an ensemble.

\section{Conclusions and Managerial Implications}

The purpose of this study was to examine the utilization of electronic channels in micro-sized brick-and-mortar firms and increase understanding of both the factors underlying the adoption and use and of the actual utilization of digital channels in marketing by identifying various levels of digital channel usage. On the basis of the results it can be stated that there are various ways in which micro firms utilize electronic channels in their marketing. Electronic channels can be used for informational purposes or for enhancing communication between the firm and its customers. Electronic channels can also be a channel for sales, or a supportive channel through which pre- and post-sales services can be provided. 
Ultimately, e-channels can be an integral part of business. How strategic the role of electronic channels eventually is depends on the external and internal factors. Whether electronic channels are parallel channels or in a more minor role in marketing, strategic planning of their use and overall role is nevertheless essential. .

This study contributes to theory by synthesizing the examination of both the underlying factors and stage-like modeling in order to formulate a clearer picture of ebusiness in micro-sized companies. Stage models, even though they are a common way of depicting e-commerce or e-business development, have been widely criticized for not taking into account various factors influencing the firm and for assuming that every firm should aim for the highest possible degree of e-business usage. The model developed in this study takes into account the influencing factors and does not assume that the ideal level of e-channel usage is the same for every company. The conceptual model suggested that from the viewpoint of the firm the level of utilization is more like an approach. The model also suggested that if the factors influencing the firm change, it could potentially move to another level of development, as the firm's approach to e-channels changes. The empirical assessment supported this proposition.

The findings also support previous studies in many ways. Firstly, this study showed that the owner-manager's motivation is one of the most influential factors determining the echannel use of a firm (Rao, Metts and Mora Monge 2003; Fillis, Johansson and Wagner 2004). Secondly, the results suggest that the awareness of the benefits (or the perceived benefits) is an important influencing factor (Ramsey et al. 2003; Dholakia and Kshetri 2004; McCole and Ramsey 2005; Chong and Pervan 2007). Thirdly, experience was seen as a potential inhibitor to e-channel utilization (Simpson and Docherty 2004). Finally, the type of the product or service was found to be one of the factors influencing the extent to which e- 
channels could be utilized, which is in line with previous literature (MacGregor and Vrazalic 2006).

Some managerial guidelines can be presented in the light of this study. By gaining a better understanding of the factors accelerating e-channel utilization, the issues that are hindering the development can be recognized and addressed, and for example skills can be developed. Most importantly, managers should keep in mind that the firm's strategy is the starting point for all development, including electronic channel utilization. Whether or not electronic channels play a minor or a major role in the business, their adoption and utilization should still always originate from the needs of the firm. E-business should not be treated as a separate part of business, but as a complementary element which can increase the value created for the customer. Thus strategic planning is important when thinking about e-channel utilization. A formal strategy is not obligatory but some deliberation regarding the objectives is nevertheless needed. Ideally, electronic channels should support the business activity and marketing as much as possible. There is no use creating a website, for instance, if its purpose and goals are not thought out properly.

As micro firms they often have somewhat limited resources to devote to marketing, even when using digital channels, it is more profitable for them to strive for long-term relationships with customers. Electronic channels play an important part in this too, and not only when attracting new customers. It is important to establish and maintain some kind of a customer database, which contains relevant information about the customer. With the help of a customer database one can document, for instance, what happens in the relationship, what transactions are made and what the customers' special needs and requirements are. With the help of this information it is possible to customize the offers to fit each customer and thus satisfy the customers' needs better. When it comes to customer relationship management, firms of this scale do not necessarily need fancy IT-systems to be able to manage their 
customer relations, but instead this can in fact be done with relatively simple and common software.

Especially in the case of very small firms and entrepreneurs the importance of outside support and cooperation should not be underestimated. For small firms it will prove very difficult to do everything by themselves, and therefore cooperation with other partners can turn out to be very productive.

Every study has certain limitations, which have to be taken into consideration. In this study the case firms are very small, which makes the research context special and thus the results are not directly applicable to other contexts or surroundings. However, generalizability was not the primary objective of this study, as the aim was to increase understanding of the phenomenon. In future research, more firms should be examined in order to find out whether similar factors and levels are found in other contexts as well or whether differences occur for example between industries. Although the case firms in this study were actually quite different from each other, they operated in a more traditional environment than for example high tech firms. In other words, the industry/sectorial factors need further examination. Moreover, this study found out that external support is very significant when it comes to the adoption and use of electronic channels, and this is a factor that requires further research, as it has not been investigated very much. Another guideline for future research could be to focus more deeply on some of the factors, for example either on the internal or the external factors. It was difficult to distinguish which factors belong to which category because of their interrelatedness. The subject would require further research in order to formulate a more precise picture of the influencing factors and their interdependencies. 


\section{References}

Adelaar, T., H. Bouwman, and C. Steinfeld, C. (2004). "Enhancing Customer Value through Click-and-Mortar E-Commerce: Implications for Geographical Market Reach and Customer Type," Telematics and Informatics 21, 167-182.

Al-Qirim, N. (2006). "Personas of E-Commerce Adoption in Small Businesses in New Zealand," Journal of Electronic Commerce in Organizations 4(3), 17-45.

Bahn, D. L., and P. P. Fischer (2003). "Clicks and Mortar: Balancing Brick and Mortar Business Strategy and Operations with Auxiliary Electronic Commerce," Information Technology and Management 4(2/3), 319-334.

Chau, S. (2003). "The Use of E-Commerce Amongst Thirty-Four Australian SMEs: An Experiment or a Strategic Business Tool?," Journal of Systems \& Information Technology 7(1), 49-66.

Chong, S., and G. Pervan (2007). "Factors Influencing the Extent of Deployment of Electronic Commerce for Small- and Medium-Sized Enterprises," Journal of Electronic Commerce in Organizations 5(1), 1-29.

Daniel, E., and H. Wilson (2002). "Adoption Intentions and Benefits Realised: A Study of ECommerce in UK SMEs," Journal of Small Business and Enterprise Development 9(4), 331348.

Dholakia, R. R., and N. Kshetri (2004). "Factors Impacting the Adoption of the Internet among SMEs," Small Business Economics 23(4), 311-322.

Eisenhardt, K. M. (1989). "Building Theories from Case Study Research," Academy of Management Review 14(4), 532-550.

European Commission (2006), http://ec.europa.eu/enterprise/smes/facts_figures_en.htm, visited October 2006.

Fillis, I., U. Johansson, and B. Wagner (2003). "A Conceptualisation of the Opportunities and Barriers to E-Business Development in the Smaller Firm," Journal of Small Business and Enterprise Development 10(3), 336-344.

Fillis, I., U. Johansson, and B. Wagner (2004). "A Qualitative Investigation of Smaller Firm E-Business Development," Journal of Small Business and Enterprise Development 11(3), 349-361.

Fillis, I., and B. Wagner (2005). "E-Business Development: An Exploratory Investigation of the Small Firm," International Small Business Journal 23(6), 604-634.

Foley, P., and M. Ram (2002). "The Use of Online Technology by Ethnic Minority Businesses: A Comparative Study of the West Midlands and UK," De Montfort University, Leicester. Available at:

http://www.sbs.gov.uk/content/research/EBM_IT.pdf 
Fry, J., D. Tyrrall, G. Pugh, and J. Wyld (2004). "The Provision and Accessibility of Small Business Web Sites: A Survey of Independent UK Breweries," Journal of Small Business and Enterprise Development 11(3), 302-314.

Levenburg, N. M., T. C. Dandridge, and S. Hong (2001). "Marketing via the Internet: Micro Firms and E-Commerce. Proceedings of the American Marketing Association Summer Educators' Conference 12, 97-103.

Levy, M., P. Powell, and L. Worrall (2005). "Strategic Intent and E-Business in SMEs: Enablers and Inhibitors," Information Resources Management Journal 18(4), 1-20.

MacGregor, R. C., and L. Vrazalic (2006). "E-Commerce Adoption Barriers in Small Businesses and the Differential Effects of Gender," Journal of Electronic Commerce in Organisations 4(2), 1-22.

Martin, L. M., and H. Matlay (2001). "Blanket Approaches to Promoting ICT in Small Firms: Some Lessons from the DTI Ladder Adoption Model in the UK," Internet Research 11(5), 399-410.

Matlay, H. (2000). "Training in the Small Business Sector of the British Economy," in Enterprise and Small Business: Principles, Policy and Practice. Eds. S. Carter, and D. JonesEvans. London: Addison Wesley Longman.

McCole, P., and E. Ramsey (2005). "A Profile of Adopters and Non-adopters of E-commerce in SME Professional Service Firms," Australasian Marketing Journal 13(1), 36-48.

Payne, A., and P. Frow (2004). "The Role of Multichannel Integration in Customer Relationship Management," Industrial Marketing Management 33(6), 527-538.

Pires, G. D., and J. Aisbett (2003). "The Relationship between Technology Adoption and Strategy in Business-to-Business Markets. The Case of E-commerce," Industrial Marketing Management 32(4), 291-300.

Pk-yritysbarometri (2007), www.yrittajat.fi/sy/home.nsf/www/pk_yritysbarometri_2_2007, visited 15.1.2008.

Poon, S., and P. Swatman (1999). "An Exploratory Study of Small Business Internet Commerce Issues,” Information and Management 35(1), 9-18.

Ramsey, E., P. Ibbotson, J. Bell, and B. Gray (2003). "E-Opportunities of Service Sector SMEs: An Irish Cross-Border Study," Journal of Small Business and Enterprise Development 10(3), 250-264.

Rao, S. S., G. Metts, and C. A. Mora Monge (2003). "Electronic Commerce Development in Small and Medium Sized Enterprises. A Stage Model and Its Implications," Business Process Management Journal 9(1), 11-32.

Ravi, S. (2005). “Optimal Search Engine Marketing Strategy,” International Journal of Electronic Commerce 10(1), 9-25. 
Schaper, M., M. Campo and J. Imukuka (2005). "The Training and Management Development Needs of Micro-Firms," Training and Management Development Methods 19(2), 13-22.

Simpson, M., and A. J. Docherty (2004). "E-commerce Adoption Support and Advice for UK SMEs," Journal of Small Business and Enterprise Development 11(3), 315-328.

Stone, M. (2003). "SME E-Business and Supplier-Customer Relations," Journal of Small Business and Enterprise Development 10(3), 345-353.

Strauss, J., A. El-Ansary, and R. Frost (2006). E-Marketing (fourth edition). New Jersey: Pearson Prentice-Hall.

Taylor, M., and A. Murphy (2004). "SMEs and E-Business," Journal of Small Business and Enterprise Development 11(3), 280-289.

Thong, J. Y. L. (1999). “An Integrated Model of Information Systems Adoption in Small Businesses," Journal of Management Information Systems 15(4), 187-214.

Turban, E., D. King, J. Lee, M. Warkentin, and M. H. Chung (2002). Electronic Commerce A Managerial Perspective. New Jersey: Pearson Prentice Hall.

Yin, R. K. (2003). Case Study Research: Design and Methods (3rd edition). Thousand Oaks: Sage Publications. 


\section{Tables and figures}

Table 1

Models of e-business development in SMEs

\begin{tabular}{|c|c|c|}
\hline Author(s) & Model & Key findings \\
\hline $\begin{array}{l}\text { DTI (Department of Trade and } \\
\text { Industry, UK) (via Martin and } \\
\text { Matlay 2001) }\end{array}$ & DTI adoption ladder & $\begin{array}{l}\text { Linear model comprising of } \\
\text { five stages; } 1 \text {. e-mail, } 2 \text {. } \\
\text { website, } 3 \text {. e-commerce, } 4 \text {. e- } \\
\text { business, } 5 \text {. transformed } \\
\text { organisations. }\end{array}$ \\
\hline $\begin{array}{l}\text { Rao, Metts and Mora Monge } \\
(2003)\end{array}$ & $\begin{array}{l}\text { Stage model for e-commerce } \\
\text { development in SMEs }\end{array}$ & $\begin{array}{l}\text { Four stages of development, } \\
\text { each having certain facilitators } \\
\text { and barriers. Stages; presence, } \\
\text { portals, transactions integration, } \\
\text { enterprises integration. }\end{array}$ \\
\hline $\begin{array}{l}\text { Foley and Ram (2002); Taylor } \\
\text { and Murphy (2004) }\end{array}$ & $\begin{array}{l}\text { PITs (Publicise, Interact, } \\
\text { Transform) model of ICT } \\
\text { adoption by SMEs }\end{array}$ & $\begin{array}{l}\text { ICT can be introduced into } \\
\text { different activities (for example } \\
\text { logistics, marketing and sales) } \\
\text { at different rates. Three } \\
\text { increasingly sophisticated } \\
\text { activities; publicise (P) } \\
\text { information, interact (I) with } \\
\text { customers and suppliers, } \\
\text { transform }(\mathrm{T}) \text { business activities }\end{array}$ \\
\hline Chau (2003) & $\begin{array}{l}\text { Four-phase model of SME e- } \\
\text { commerce utilization and } \\
\text { business transformation }\end{array}$ & $\begin{array}{l}\text { Conceptual model consisting of } \\
\text { four phases; } 1 \text {. static presence, } \\
2 \text {. e-commerce as adjunct to } \\
\text { traditional business, } 3 \text {. } \\
\text { integration of e-commerce to } \\
\text { business processes, } 4 \text {. creating a } \\
\text { virtual business structure }\end{array}$ \\
\hline
\end{tabular}

\section{Table 2}

Five approaches to clicks and mortar (adapted from Bahn and Fischer 2003)

\begin{tabular}{ll} 
Front lobby & $\begin{array}{l}\text { Creating a general online listing for the firm and its product, } \\
\text { when product features and/or supply chain issues constrain } \\
\text { any significant use of e-commerce even for product support } \\
\text { and marketing activities }\end{array}$ \\
Maximize product profile & $\begin{array}{l}\text { Using e-commerce only to promote and provide post-sales } \\
\text { service for the firm's products/services, but not as a channel } \\
\text { for sales } \\
\text { Undundle burdensome transactions } \\
\text { Utilizing e-commerce as a support channel to expedite } \\
\text { process components that have been traditionally inexpedient } \\
\text { or burdensome within brick-and-mortar transactions } \\
\text { Uarallel lines } \\
\text { Utilizing e-commerce as an independent, full-ledged } \\
\text { channel that is intentionally subordinate to brick-and-mortar } \\
\text { channel } \\
\text { Integration of the brick-and-mortar and online channels to } \\
\text { the greatest possible extent }\end{array}$ \\
\hline
\end{tabular}


Table 3

Case Companies

\begin{tabular}{|c|c|c|c|c|}
\hline Case company & Description & Industry & $\begin{array}{c}\text { Age in } 2007 \\
\text { (years) }\end{array}$ & $\begin{array}{c}\text { Staff } \\
\text { (owner- } \\
\text { manager + } \\
\text { other staff) }\end{array}$ \\
\hline \multicolumn{5}{|l|}{ Retailers } \\
\hline Articraft & $\begin{array}{l}\text { tourism, gift shop, } \\
\text { handicraft products }\end{array}$ & retail, b-to-c & 3 & $\begin{array}{l}2+1 \text { (seasonal } \\
\text { worker) }\end{array}$ \\
\hline Finmade & $\begin{array}{l}\text { manufactures and } \\
\text { sells wooden design } \\
\text { products }\end{array}$ & $\begin{array}{l}\text { manufacturing, } \\
\text { retail, mainly } \\
\text { b-to-b }\end{array}$ & $9(19)$ & $\begin{array}{l}1+2 \text { (designer } \\
\text { and trainee) }\end{array}$ \\
\hline Frame & $\begin{array}{l}\text { manufactures and } \\
\text { sells wooden picture } \\
\text { frames }\end{array}$ & $\begin{array}{l}\text { manufacturing, } \\
\text { retail, mainly } \\
\text { b-to-b }\end{array}$ & 14 & $1+1$ \\
\hline Reseller & importer, reseller & retail, b-tob & 2 & $1+1$ \\
\hline \multicolumn{5}{|l|}{ Services } \\
\hline Constructor & construction & services, b-b & 15 & $1+2$ \\
\hline Designor & $\begin{array}{l}\text { industrial design, } \\
\text { consulting }\end{array}$ & services, b-to-b & 3 & $1+1$ (trainee) \\
\hline Entertainer & tourism, services & $\begin{array}{l}\text { services, b-to-b, b- } \\
\text { to-c }\end{array}$ & 5 & $1+1$ \\
\hline Holidecor & interior design & $\begin{array}{l}\text { services, b-to-b, } \\
\text { b-to-c }\end{array}$ & 18 & 1 \\
\hline Ind-design & $\begin{array}{l}\text { industrial design, } \\
\text { design management, } \\
\text { consulting }\end{array}$ & services, b-to-b & 13 & 1 \\
\hline Maintainer & maintenance & services, b-to-b & 10 & $1+3$ \\
\hline
\end{tabular}


Figure 1

Conceptual model for the study

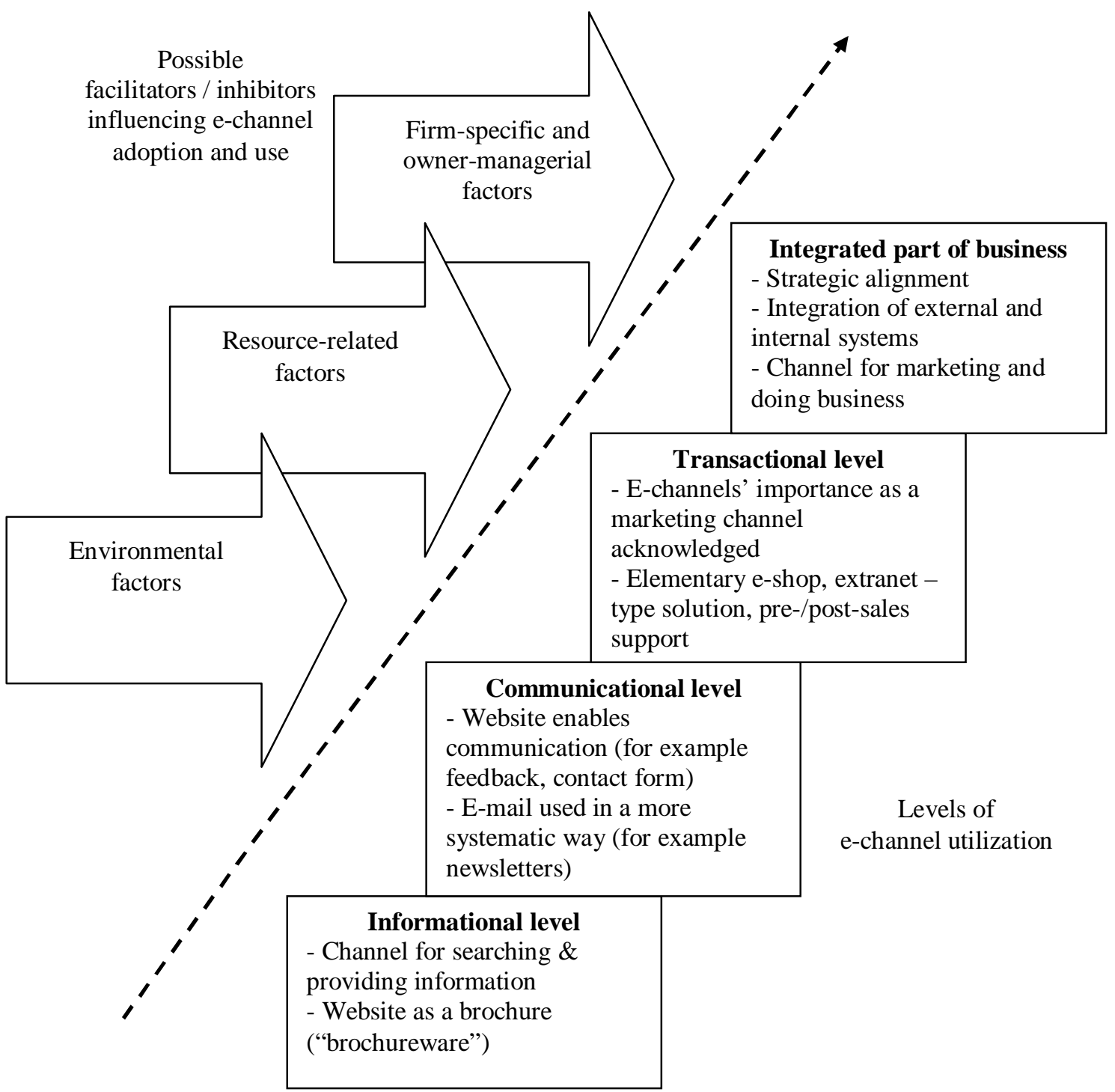


Figure 2

Identified levels of e-channel utilization in the case firms

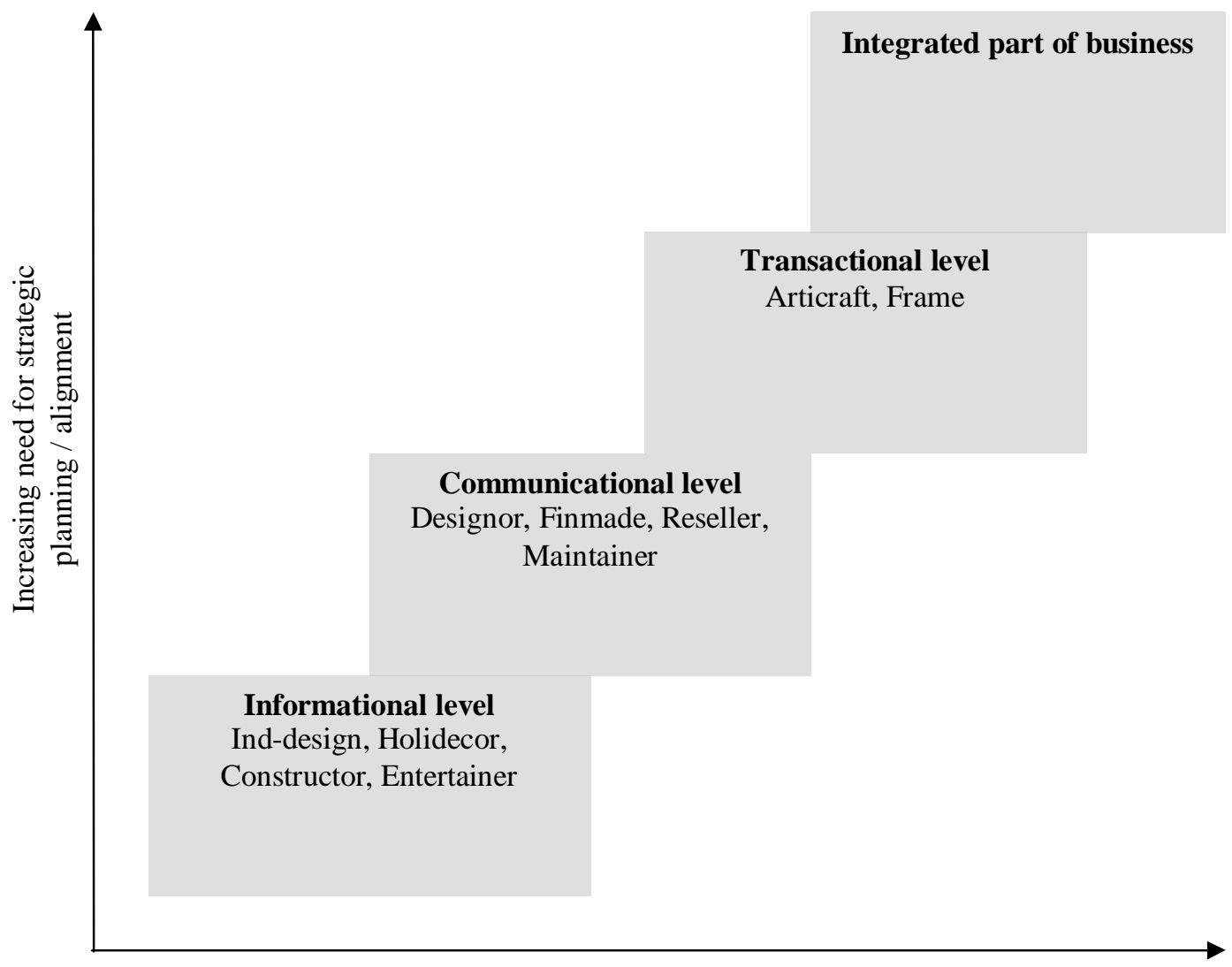

Increasing technological sophistication 
Figure 3

Empirically justified model of e-channel utilization in micro firms

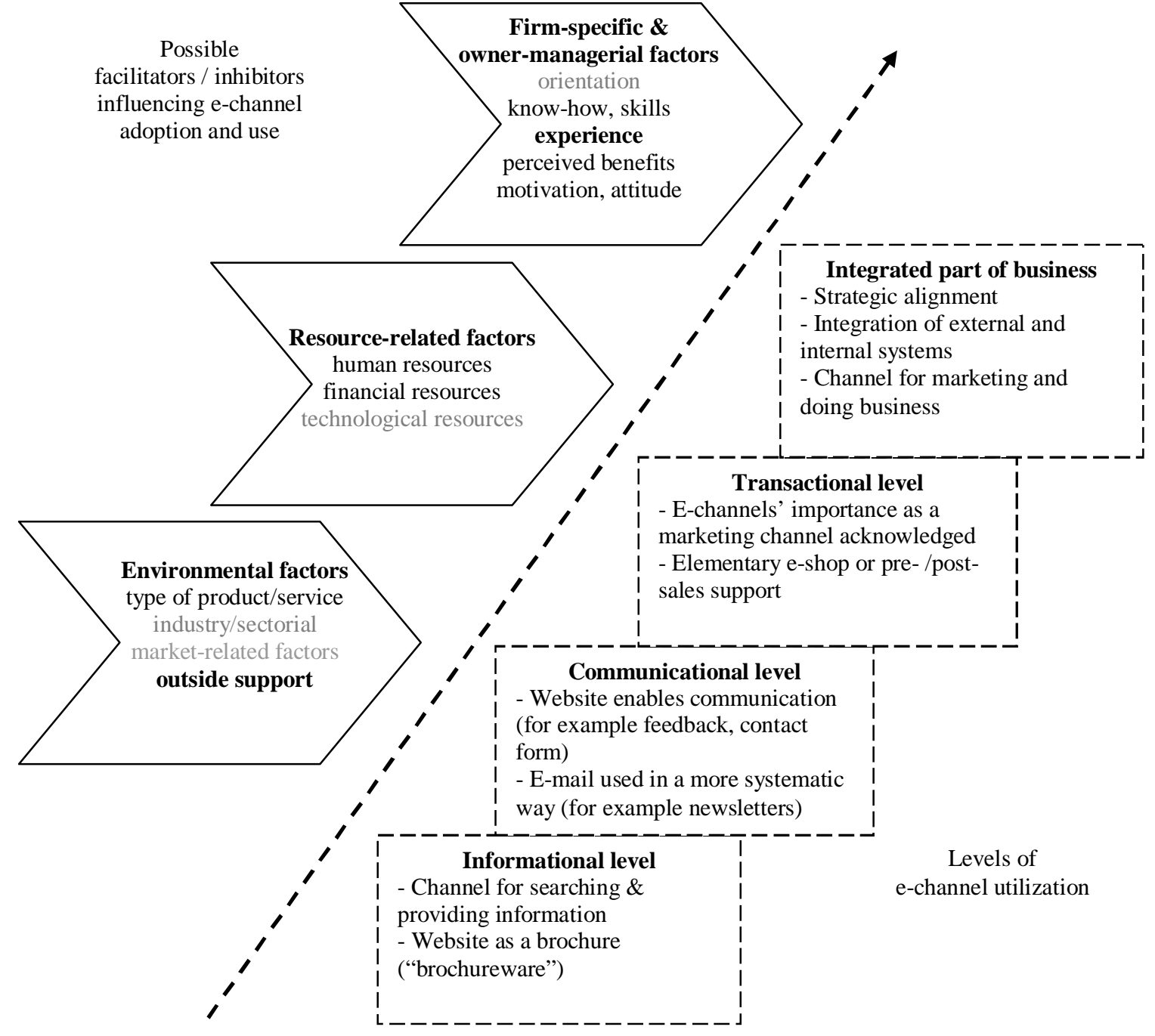

